\title{
Synthetic Oligosaccharide-Based Vaccines Protect Mice from Clostridioides difficile Infections
}

Felix Broecker, ${ }^{\dagger, \downarrow} \star \nabla$ Erik Wegner, ${ }^{\S, \nabla}$ Bruna M. S. Seco, ${ }^{\dagger, \ddagger}$ Paulina Kaplonek, ${ }^{\dagger \neq}$ Maria Bräutigam, ${ }^{\dagger, \ddagger}$

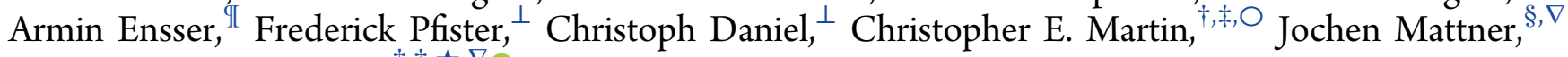
and Peter H. Seeberger*, $+, \star, \nabla_{(\mathbb{C}}$

${ }^{\dagger}$ Department of Biomolecular Systems, Max Planck Institute of Colloids and Interfaces, Am Mühlenberg 1, 14424 Potsdam, Germany

${ }^{\ddagger}$ Institute of Chemistry and Biochemistry, Freie Universität Berlin, Arnimallee 22, 14195 Berlin, Germany

${ }^{\S}$ Mikrobiologisches Institut-Klinische Mikrobiologie, Immunologie und Hygiene, Universitätsklinikum Erlangen and Friedrich-Alexander Universität Erlangen-Nürnberg, 91054 Erlangen, Germany

${ }^{\mathbb{I}}$ Virologisches Institut, Universitätsklinikum Erlangen, Friedrich-Alexander-Universität Erlangen-Nürnberg, Erlangen, Germany

${ }^{\perp}$ Department of Nephropathology, Friedrich-Alexander University of Erlangen-Nürnberg, Erlangen, Germany

\author{
Supporting Information
}

ABSTRACT: Infections with Clostridioides difficile (formerly Clostridium difficile) have increased in incidence, morbidity, and mortality over the past decade. Preventing infections is becoming increasingly important, as frontline antibiotics become less effective and frequently induce recurrence by disrupting intestinal microbiota. The clinically most advanced vaccine approaches prevent symptoms once $C$. difficile infection is established by inducing immunity to secreted clostridial cytotoxins. However, they do not inhibit bacterial colonization and thereby favor asymptomatic carriage.

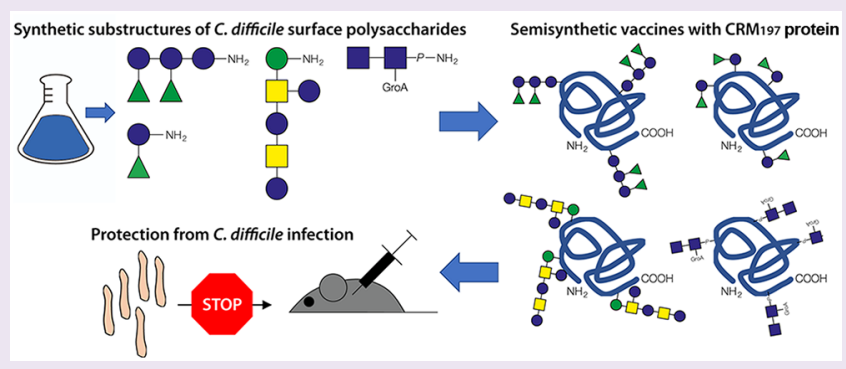
Synthetic oligosaccharides resembling the C. difficile surface glycans PS-I, PS-II, and PS-III are immunogenic and serve as basis for colonization-preventing vaccines. Here, we demonstrate that glycoconjugate vaccine candidates based on synthetic oligosaccharides protected mice from infections with two different $C$. difficile strains. Four synthetic antigens, ranging in size from disaccharides to hexasaccharides, were conjugated to $\mathrm{CRM}_{197}$, which is a carrier protein used in commercial vaccines. The vaccine candidates induced glycan-specific antibodies in mice and substantially limited $C$. difficile colonization and colitis after experimental infection. The glycoconjugates ameliorated intestinal pathology more substantially than a toxin-targeting vaccine. Colonization of the gut by $C$. difficile was selectively inhibited while intestinal microbiota remained preserved. Passive transfer experiments with anti-PS-I serum revealed that protection is mediated by specific antiglycan antibodies; however, cell-mediated immunity likely also contributed to protection in vivo. Thus, glycoconjugate vaccines against $C$. difficile are a complementary approach to toxin-targeting strategies and are advancing through preclinical work.

\section{INTRODUCTION}

Clostridioides difficile is the leading cause of antibiotic-induced bacterial colitis and diarrhea worldwide. ${ }^{1,2}$ Risk factors for $C$. difficile infections (CDIs) include broad-spectrum antibiotic use, hospitalization, and advanced age. ${ }^{3}$ Over 450,000 cases cause about 30000 deaths and over $\$ 4.8$ billion medical costs per year in the United States. ${ }^{2}$ Recent increases in incidence and case-fatality rates have been partially attributed to emerging hypervirulent strains with elevated production of the virulence factors $\mathrm{TcdA}$ and $\mathrm{TcdB}$ that mediate $\mathrm{CDI}$ pathology. ${ }^{1,3-5}$

The recommended first-line treatment for CDI-antibiotics-paradoxically cause disease recurrence in ca. $20 \%$ of patients by disrupting gut microbiota. ${ }^{1,5,6}$ As antibiotics reach their limits, anti-CDI vaccine candidates have been pursued and three are being clinically tested. ${ }^{7}$ All three induce antitoxin immunity, but they do not prevent bacterial colonization. ${ }^{7}$ As antitoxin IgG correlates with asymptomatic carriage, toxinbased vaccines may even expand the presence of $C$. difficile in the population. ${ }^{8,9}$ Vaccines targeting the bacterial surface, in contrast, could limit the human reservoir. ${ }^{10}$ Recently, $C$. difficile surface polysaccharides, PS-I, PS-II, and PS-III that are essential for bacterial survival and virulence, ${ }^{11}$ emerged as auspicious targets for colonization-preventing vaccines. $8,12,13$ Glycoconjugates (protein-linked glycans) with isolated PS-II and PS-III were immunogenic in small animals. ${ }^{14,15}$ However, the natural glycans are challenging to study, because of weak and inconsistent expression in bacterial culture. ${ }^{8}$ We have

Received: August 7, 2019

Accepted: November 6, 2019

Published: November 6, 2019 

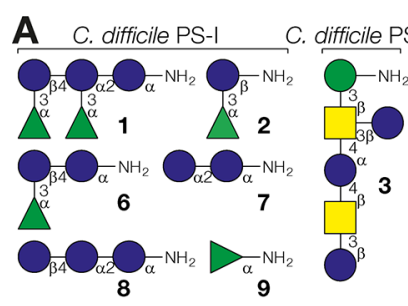

Control

Kdo $\bar{\alpha} \mathrm{NH}_{2} \mathbf{5}$

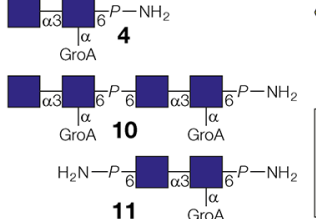

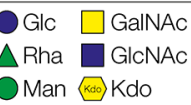

B

\begin{tabular}{cccc}
\hline $\begin{array}{c}\text { Oligosaccharide } \\
\text { (amount) }\end{array}$ & $\begin{array}{c}\text { Spacer molecule } \\
\text { (amount) }\end{array}$ & $\begin{array}{c}\text { Amount } \\
\text { of CRM197 }\end{array}$ & $\begin{array}{c}\text { Compound } \\
\text { no. }\end{array}$ \\
\hline $\mathbf{1}(1 \mathrm{mg} / 1.1 \mu \mathrm{mol})$ & $\operatorname{DNAP}(2.6 \mathrm{mg} / 6.8 \mu \mathrm{mol})$ & $1.3 \mathrm{mg}$ & $\mathbf{1 2}$ \\
$\mathbf{2}(1 \mathrm{mg} / 2.4 \mu \mathrm{mol})$ & DNAP $(5.7 \mathrm{mg} / 14.6 \mu \mathrm{mol})$ & $0.7 \mathrm{mg}$ & $\mathbf{1 3}$ \\
$\mathbf{3}(1 \mathrm{mg} / 0.9 \mu \mathrm{mol})$ & $\operatorname{DNAP}(2.1 \mathrm{mg} / 5.4 \mu \mathrm{mol})$ & $0.5 \mathrm{mg}$ & $\mathbf{1 4 a}$ \\
$\mathbf{3}(1 \mathrm{mg} / 0.9 \mu \mathrm{mol})$ & $\operatorname{DSAP}(3.1 \mathrm{mg} / 9.1 \mu \mathrm{mol})$ & $0.4 \mathrm{mg}$ & $\mathbf{1 4}$ \\
$\mathbf{4}(1.4 \mathrm{mg} / 2 \mu \mathrm{mol})$ & $\operatorname{DNAP}(4.7 \mathrm{mg} / 12.1 \mu \mathrm{mol})$ & $0.7 \mathrm{mg}$ & $\mathbf{1 5}$ \\
$\mathbf{5}(1.4 \mathrm{mg} / 4.3 \mu \mathrm{mol})$ & DNAP $(10.1 \mathrm{mg} / 26 \mu \mathrm{mol})$ & $0.5 \mathrm{mg}$ & $\mathbf{1 6 a}$ \\
$\mathbf{5}(2 \mathrm{mg} / 6.2 \mu \mathrm{mol})$ & $\operatorname{DSAP}(21 \mathrm{mg} / 61.9 \mu \mathrm{mol})$ & $1 \mathrm{mg}$ & $\mathbf{1 6}$ \\
\hline
\end{tabular}

C

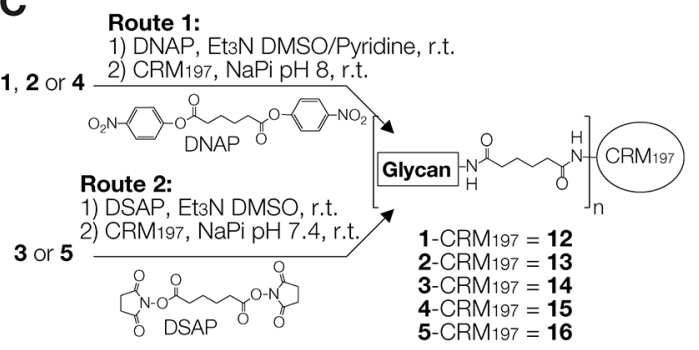

D

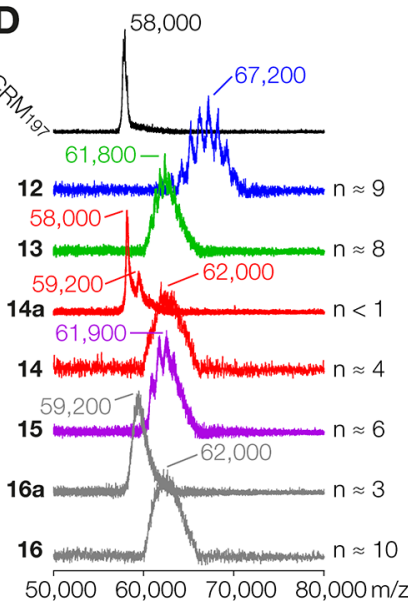

E

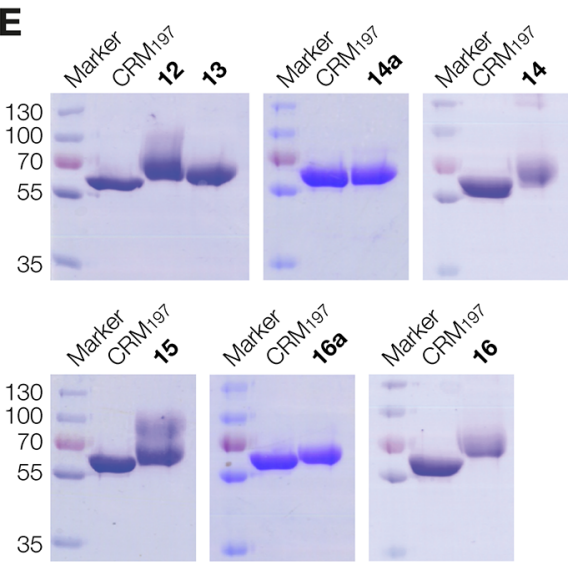

Figure 1. Preparation of vaccine candidates: (A) oligosaccharides used, (B) glycoconjugates prepared, and (C) two chemical conjugation strategies to attach oligosaccharides to $\mathrm{CRM}_{197}$ are shown. (D) MALDI-TOF MS spectra of $\mathrm{CRM}_{197}$ and glycoconjugates. Average antigen loading ( $n$ ) is shown to the right. (E) SDS-PAGE gels of $\mathrm{CRM}_{197}$ and glycoconjugates; numbers shown to the left are marker sizes in kDa. See the Supporting Information for full structures of oligosaccharides 1-11 and 12 as an exemplary glycoconjugate (Supplemental Figure S1).

previously reported that synthetic PS-I, PS-II, and PS-III oligosaccharides (Figure 1A) are immunogenic in mice when linked to the $\mathrm{CRM}_{197}$ carrier protein, which is a nontoxic mutant of diphtheria toxin that allows for efficient covalent attachment of synthetic oligosaccharides and is used in licensed glycoconjugate vaccines. ${ }^{16-23}$ In 2011, we reported the synthesis of the hexasaccharide repeating unit of PS-II 3 that, when linked to $\mathrm{CRM}_{197}$, was immunogenic in mice and was used to generate PS-II specific monoclonal antibodies (mAbs). ${ }^{16}$ In the same year, we achieved the first synthesis of the pentasaccharide repeating unit of PS-I 1 that was likewise immunogenic in mice when formulated as a glycoconjugate with $\mathrm{CRM}_{197}{ }^{17,19}$ Studying smaller substructures (2-9) revealed the disaccharide $\mathbf{2}$ as the minimal epitope of PS-I, which was able to induce antibodies in mice that cross-reacted with the entire repeating unit. ${ }^{19}$ Furthermore, we generated mAbs against PS-I that recognized both 1 and $2 .^{20}$ In 2013, we reported the first synthesis and antigenicity of PS-III oligomers (monomer 4, dimer 10, monomer with two linkers 11) ${ }^{18}$ and subsequently showed that $\mathbf{1 0}$ was immunogenic as a glycoconjugate with $\mathrm{CRM}_{197}$ and protected mice from challenge with $C$. difficile. ${ }^{21}$ In the present study, we evaluated the protective efficacy of various glycoconjugates prepared by linking synthetic glycans of PS-I (1 and 2), PS-II (3), and PSIII (4) to $\mathrm{CRM}_{197}$. We show that these semisynthetic vaccine candidates protect from CDI in a murine challenge model more effectively than an antitoxin vaccine candidate.

\section{RESULTS AND DISCUSSION}

Preparation of Glycoconjugates. We prepared $\mathrm{CRM}_{197}$ glycoconjugates with the PS-I repeat unit $\mathbf{1}^{17,19}$ its minimal epitope $\mathbf{2},{ }^{19,20}$ the PS-II repeat unit $3,^{16}$ and PS-III disaccharide $4^{21}$ (Figure $1 \mathrm{~A}$ ). We have recently shown that (i) a $\mathrm{CRM}_{197}$ glycoconjugate with PS-III tetrasaccharide 10 elicited protective IgG in mice, and (ii) 4 is the minimal epitope of $10 .{ }^{21}$ Although 4 may be less immunogenic than the larger 10, charged oligosaccharides and even monosaccharides can elicit strong IgG responses. ${ }^{14,24}$ Thus, here, we investigated if 4 is also able to induce protection from CDI. The lipopolysaccharide component 3-deoxy-D-manno-oct-2-ulosonic acid (Kdo) 5 served as a nonrelated control antigen. ${ }^{24}$ All oligosaccharides were equipped with aminopentyl linkers. Additional oligosaccharides of PS-I (6-9) and PS-III (10, 11) served to assess IgG specificities later. Cross-linking 1, 2, and 4 to $\mathrm{CRM}_{197}$ was achieved with di-p-nitrophenyl adipate (DNAP), ${ }^{20,25}$ whereas, for $\mathbf{3}$ and $\mathbf{5}$, di-N-succinimidyl adipate (DSAP) was used, as coupling with DNAP was inefficient (Figure $1 \mathrm{~B}$ ). Reaction products with both cross-linkers yielded identical adipoyl linking moieties between oligosaccharides and protein (Figure 1C). Mass increases of the glycoconjugates to $\mathrm{CRM}_{197}$ determined by MALDI-TOF MS were used to determine the oligosaccharide/carrier molar ratios (Figure 1D). Glycoconjugates 12 (prepared with 1/DNAP), 13 (2/ DNAP), 14 (3/DSAP), 15 (4/DNAP), and 16 (5/DSAP) had average oligosaccharide/carrier ratios between 4 and 10, which are loadings suitable to elicit antioligosaccharide IgG in mice. $^{16,19,2 \mathrm{P}}$ Glycoconjugates 14a (3/DNAP) and 16a (5/ DNAP) with antigen loadings below 4 were not considered for further experiments (Figure 1D). Mass increases to $\mathrm{CRM}_{197}$ were qualitatively confirmed by SDS-PAGE (Figure 1E).

Immunogenicity Studies in Mice. Next, immune responses to 12-16 were evaluated in mice. Mice were selected as model animals because they allow for replication of C. difficile in the colon, similar to humans, and also develop an inflammatory response upon infection. ${ }^{26}$ We supplemented $\mathbf{1 2}$ and $\mathbf{1 5}$ with the FDA-approved adjuvant aluminum hydroxide 
A
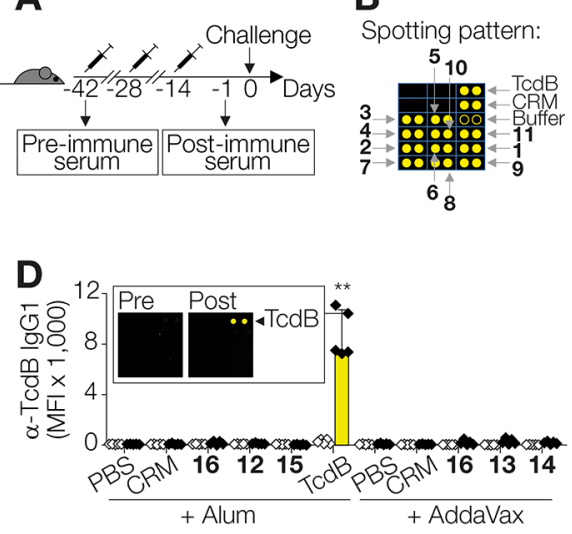

$\mathbf{F}$
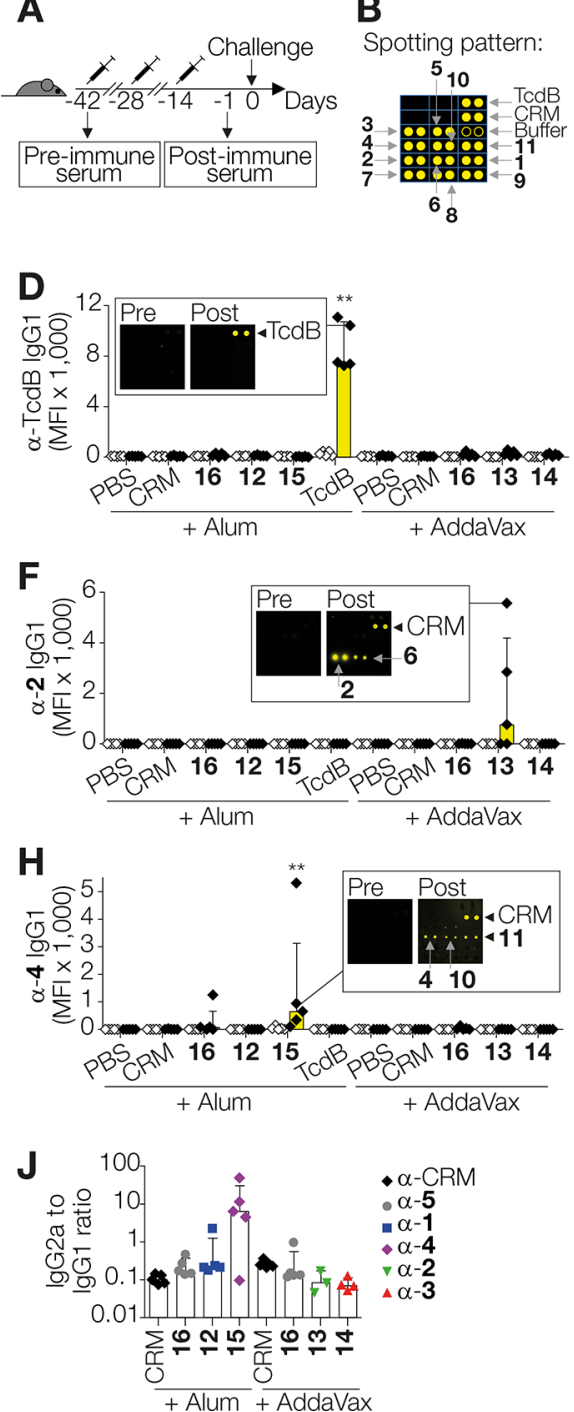
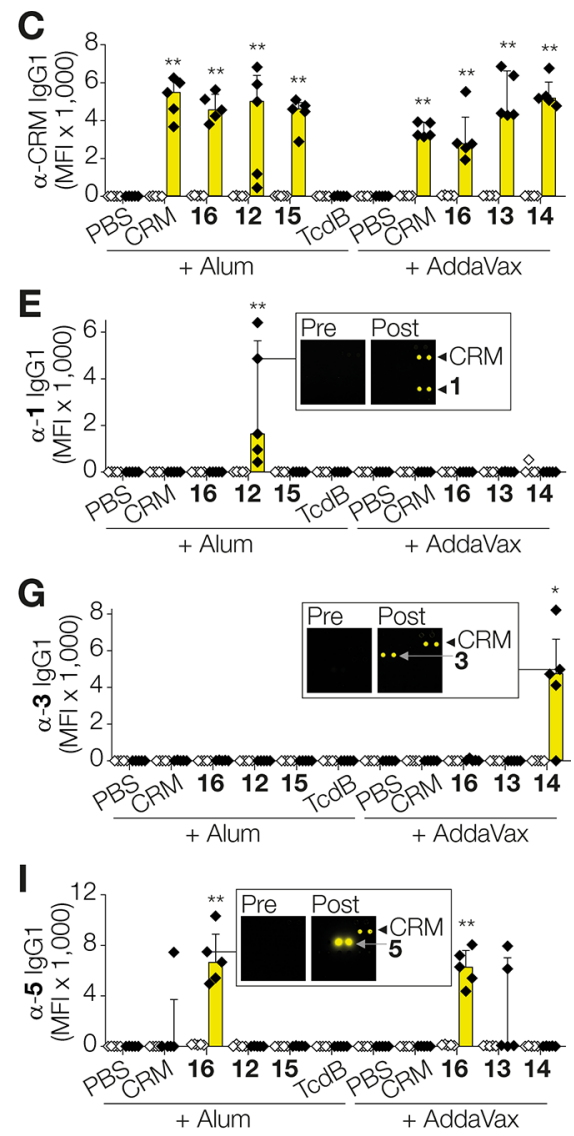

Figure 2. Vaccinated mice produce glycan-specific IgG. (A) Mice were immunized three times with glycoconjugates, CRM 197 or PBS. Sera at indicated time points were subjected to microarray-assisted IgG analysis. (B) Microarray spotting pattern. Oligosaccharides were spotted in duplicates at $0.1 \mathrm{mM}$, proteins at $1 \mu \mathrm{M}$. (C-I) Serum IgG1 levels to indicated antigens expressed as MFI values. Diamonds represent individual mice (white represents preimmune, black represents postimmune). Shown is the average of two independent experiments in duplicates. Bars show median + interquartile range of five mice. Significance was inferred by two-tailed Mann-Whitney $U$ tests (preimmune versus postimmune) with (*) $P \leq 0.05$ and $(* *) P \leq 0.01$. Insets show exemplary microarray scans. (J) IgG2a:IgG1 ratios determined by dividing microarray-inferred MFI signals of individual mice. Only mice with detectable IgG levels are represented. Bars show mean + SEM.

(Alum) that enhanced murine IgG responses to glycoconjugates with 1 and $\mathbf{1 0}$ previously. ${ }^{19,21}$ Since 2 requires a Th1directing immunostimulant to elicit $\mathrm{IgG},{ }^{19}$ we formulated 13 with AddaVax, which is a water-in-oil emulsion adjuvant similar to MF59 used in licensed influenza vaccines. ${ }^{27}$ We also used AddaVax for 14, because Alum or Freund's adjuvant did not support induction of detectable anti-3 IgG (Supplemental Figures $2 \mathrm{~A}$ and $2 \mathrm{~B}$ in the Supporting Information). PBS, $\mathrm{CRM}_{197}$, or $\mathbf{1 6}$ with Alum or AddaVax served as controls. A toxin-based vaccine candidate consisted of Alum-adjuvanted formalin-inactivated $\mathrm{TcdB}$, similar to vaccines currently studied in humans. ${ }^{7}$ A TcdA component was omitted since C. difficile strain M68 used for challenge expresses TcdB but not TcdA. ${ }^{28}$

Groups of five mice were immunized three times every two weeks with glycoconjugates at doses corresponding to $1 \mu \mathrm{g}$ oligosaccharide (Figure 2A). Inactivated TcdB was administered at $75 \mu \mathrm{g}$ per dose $(100 \mu \mathrm{g}$ induced $92 \%$ seroconversion in humans, ${ }^{29}$ while $5 \mu \mathrm{g}$ administered s.c. protected hamsters from lethal $C$. difficile challenge ${ }^{30}$ ). Sera before first immunization and 13 days after the third injection were subjected to microarray-assisted antibody analysis, ${ }^{18-21}$ with slides presenting 1-11, $\mathrm{CRM}_{197}$, and TcdB. Oligosaccharides were spotted in duplicates at $0.1 \mathrm{mM}$ and proteins at $1 \mu \mathrm{M}$, such that one slide contained 64 identical subarrays with $6 \times 6$ spots (Figure 2B). First, we measured IgG1, the predominant subtype elicited against $\mathbf{1}$ previously, ${ }^{20}$ to the various antigens. All mice that received either $\mathrm{CRM}_{197}$ or any glycoconjugate mounted IgG1 to $\mathrm{CRM}_{197}$, as expected (see Figure 2C). Similarly, 5/5 animals immunized with toxoid raised anti-TcdB IgG1 (Figure 2D). All mice immunized with 12, 3/5 of mice injected with 13 , and $4 / 5$ of mice immunized with 14 or 15 developed detectable IgG1 levels, relative to the respective oligosaccharide immunogen (Figures 2E-H), and 16 elicited IgG1 to 5 in all 10 animals with both adjuvants (see Figure 2I). 
A
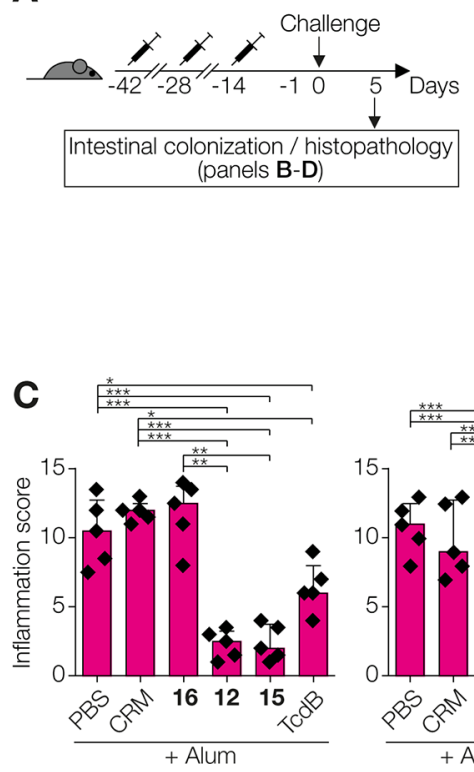

B

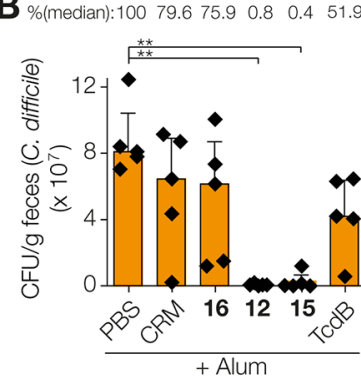

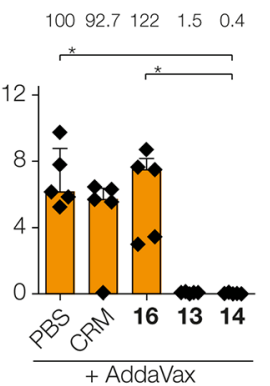

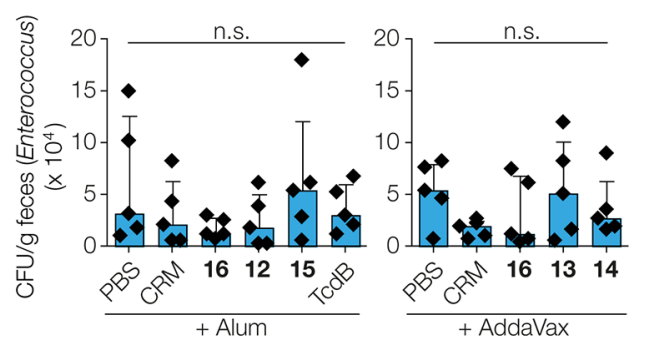

D
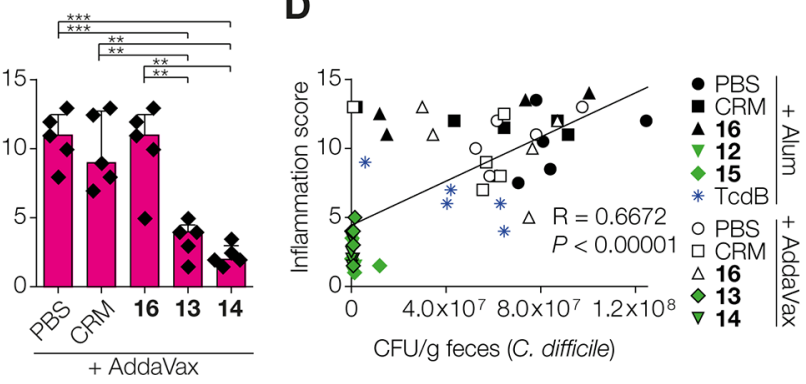

Figure 3. Vaccination with glycoconjugates protects mice from $C$. difficile colonization and colitis. (A) Five days postchallenge feces were analyzed for C. difficile and Enterococcus spp. CFUs and histopathological alterations. (B-D) Results of initial challenge studies with M68 (panel (B) shows results of CFU plating assays, panel (C) shows inflammation scores, and (D) correlation of C. difficile colonization ( $x$-axis) and inflammation score ( $y$-axis). Symbols represent individual mice $(R=$ Pearson coefficient). Significance in panels $(B)$ and $(C)$ was inferred by Dunn-corrected KruskalWallis tests $[(*) P \leq 0.05,(* *) P \leq 0.01$, and $(* *) P \leq 0.001$; n.s. $=$ not significant $(P>0.05)]$.

IgG1 raised with 15 recognized PS-III oligosaccharides 10 and 11, in addition to immunogen 4 (Figure $2 \mathrm{H}$ ). IgG1 raised with 13 bound to immunogen 2 and 6 with an additional reducing end glucose (Figure 2F). Antibodies did not cross-react between the different groups of antigens (e.g., IgG to 1 did not bind to PS-II, PS-III, or Kdo oligosaccharides). One animal that received 16 produced IgG1 to 4 , and one mouse immunized with $\mathrm{CRM}_{197}$, as well as two mice injected with 13, developed IgG1 to 5. These unexpected IgG responses may have resulted from exposure to antigenically related bacterial molecules. For instance, Kdo, which is a lipopolysaccharide component found in all Gram-negative bacteria, is a potent immunogen, ${ }^{24}$ which may explain the observed anti-5 IgG. Similar trends seen for IgG1 were also observed for IgG2a (Supplemental Figures 3A-3G in the Supporting Information), whereby one mouse immunized with 15 with undetectable anti-4 IgG1 exhibited a strong anti-4 IgG2a response (Supplemental Figure 3F in the Supporting Information). Indeed, 15 elicited antiglycan IgG with higher IgG2a:IgG1 ratios than the other glycoconjugates (Figure 2J). Thus, as suggested previously, ${ }^{21}$ PS-III may skew IgG responses to Th1, even when administered with the Th2directing Alum adjuvant. Overall, 17/20 mice vaccinated with C. difficile-specific glycoconjugates developed detectable levels of IgG to the respective oligosaccharides. No glycan-specific serum antibody binding to inactivated bacteria was detected, but it appeared that $\mathrm{CRM}_{197}$ reactive IgG bound nonspecifically to C. difficile to some degree (Supplemental Figures 4A$4 \mathrm{C}$ in the Supporting Information). Glycan-specific binding signals were likely undetectable, since polysaccharides were not expressed and/or inaccessible in cultured $C$. difficile, as observed previously for PS-I and PS-III in many C. difficile strains. ${ }^{8,14}$ While PS-II has been reported to be expressed by most strains, ${ }^{8,12,14}$ PS-II hexasaccharide-specific IgG elicited by 14 did not bind to M68 or VPI 10463 more than did CRM ${ }_{197^{-}}$ induced IgG (see Supplemental Figures 4A-S4C), indicating that these isolates may be low producers of PS-II polysaccharide in vitro.

CDI is facilitated by diminished gut bacteria, and antibioticinduced perturbations such as expanded Proteobacteria and depleted Firmicutes/Bacteroidetes may favor recurrence. ${ }^{5,31}$ It is thus desirable for an anti-C. difficile vaccine to preserve intestinal microbiota. To address this, we subjected feces of immunized mice to $16 \mathrm{~S}$ rRNA gene analysis (Supplemental Figure $5 \mathrm{~A}$ in the Supporting Information). Species-level diversity and richness were similar in vaccinated and control mice (Supplemental Figure 5B in the Supporting Information). Administration of any of the glycoconjugates preserved normal bacterial communities seen in naïve and sham-immunized mice. Bacteroidetes and Firmicutes phyla were consistently predominant, while Proteobacteria were of low abundance (Supplemental Figure 5C in the Supporting Information), characteristics of healthy microbiota. ${ }^{31}$ Similarities between groups were also observed at the order, family, and genus taxonomic levels (Supplemental Figures 5D-5F). In particular, vaccination did not reduce Lachnospiraceae and Ruminococcaceae family members that contain the majority of beneficial anti-inflammatory butyrogenic bacteria ${ }^{31}$ (Supplemental Figure $5 \mathrm{E}$ in the Supporting Information). Thus, neither vaccine candidate substantially altered the bacterial community structure. In addition, we did not find any evidence for colonization of the mice by indigenous $C$. difficile, which has been shown to sporadically contaminate mouse colonies and protect against infection with pathogenic C. difficile. ${ }^{32}$ No reads were assigned to the superordinate taxa of $C$. difficile, genus Clostridioides and family Peptostreptococcaceae, in any of the analyzed mice used for challenge experiments (Supplemental Table 1 in the Supporting Information).

Challenge Studies in Mice. To test if vaccination protected from CDI and colitis, mice were challenged with 5 $\times 10^{7}$ colony-forming units (CFUs) of the C. difficile strains M68 $28,33,34$ or VPI $10463^{26,33}$ and analyzed 5 days later for 
A

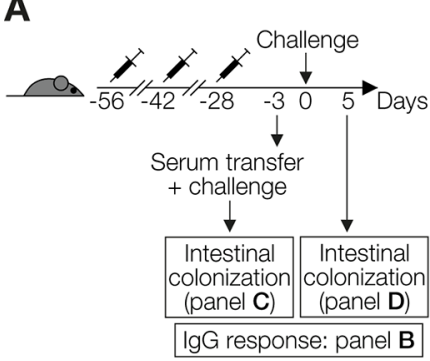

B

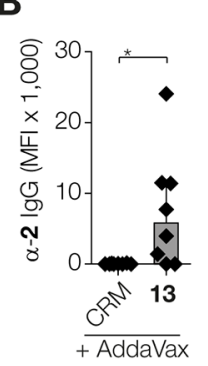

C\%

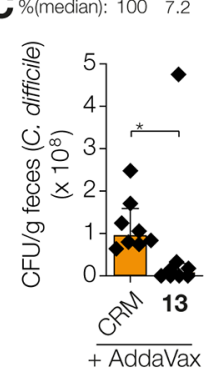

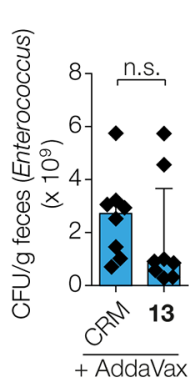

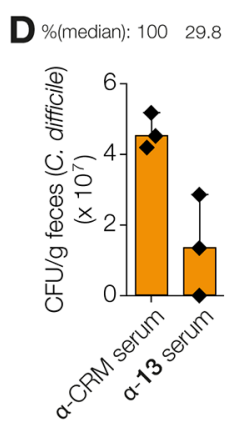

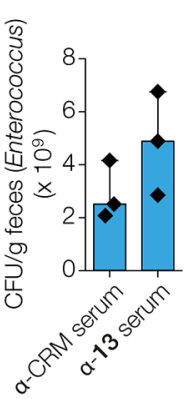

E

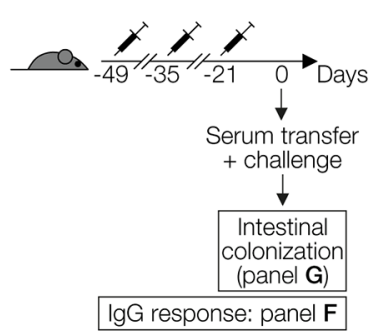

$\mathbf{F}$

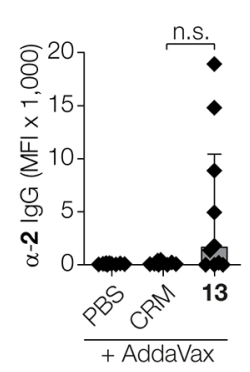

G\%(median): 10060.43 .535 .712 .5

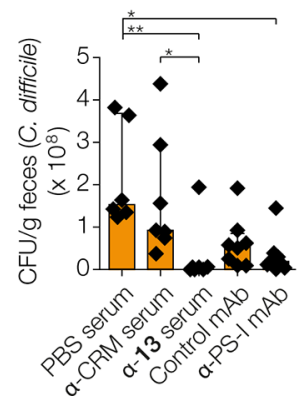

Figure 4. Challenge experiments in mice following serum transfer. (A) Mice ( $n=8$ per group) were immunized with $\mathrm{CRM}_{197}$ or 13 three times. (B) 25 days after the third vaccination, sera were subjected to microarray IgG analysis. (C) 28 days after the third vaccination, mice were challenged with VPI 10463 and intestinal colonization was analyzed. (D) Pooled sera from the same mice were used for transfer experiments into 3 recipient mice per group. (E) Mice ( $n=10$ per group) were immunized with $\mathrm{CRM}_{197}$, 13, or PBS as control. (F) Immune sera obtained 21 days after the third vaccination were subjected to microarray IgG analysis. $(\mathrm{G})$ Pooled sera from the same mice and mAbs were used for transfer experiments into 6-8 recipient mice per group. Note that $\alpha-13$ serum was pooled only from 9 of 10 mice with a signal against 2 by microarray (see panel $\mathrm{F}$ that was performed at 1:100 serum dilution; three additional mice showed a signal at 1:10 serum dilution). Bars in all panels show median + interquartile range. Significance in panels (B), (C), and (F) was inferred by two-tailed Mann-Whitney $U$ tests $[(*) P \leq 0.05$; n.s. $=$ not significant $(P>0.05)]$. Significance in panel $(\mathrm{G})$ was inferred by Dunn-corrected Kruskal-Wallis tests $[(*) P \leq 0.05 ;(* *) P \leq 0.01]$.

fecal C. difficile CFUs counts and colon pathology (Figure 3A). This time point was chosen because mice exhibit the most significant $C$. difficile-induced pathology 5 days post-infection and naturally clear the pathogen about 10 days postinfection. ${ }^{35}$ Colonic colonization levels of C. difficile M68 in mice vaccinated with 12-15 were significantly lower by up to 99.5\%, compared to PBS control mice, whereas no difference was observed for other bacteria, such as Enterococcus spp. (Figure 2B). Immunization with $\mathbf{1 5}$ (glycoconjugate with PSIII disaccharide 4) led to a $96.8 \%$ reduction of C. difficile colonization. This confirmed our previous studies in which a $\mathrm{CRM}_{197}$ glycoconjugate with PS-III tetrasaccharide 10 reduced colonization with C. difficile by $96 \%$ and $83.3 \%$, compared to nonimmunized and $\mathrm{CRM}_{197}$ immunized mice, respectively. ${ }^{21}$ Thus, both $\mathbf{4}$ and $\mathbf{1 0}$ can evoke protective IgG in mice, with $\mathbf{4}$ being easier to synthesize, ${ }^{19}$ which is an advantage toward costefficient vaccines. Neither $\mathrm{CRM}_{197}$ nor 16 significantly affected bacterial colonization, showing that protection from C. difficile was oligosaccharide-specific. Interestingly, the three mice immunized with 13 or 14 without detectable antioligosaccharide IgG were also protected. Oligosaccharide-specific IgG3 and IgM were similarly undetectable in these animals (see Supplemental Figures $3 \mathrm{D}$ and $3 \mathrm{E}$ ); perhaps they were too scarce or of too low affinity to be detectable by microarray. In addition, antibody-independent mechanisms may have contributed to inhibition of bacterial colonization. ${ }^{36,37}$ Expectedly, the $\mathrm{TcdB}$ vaccine did not significantly reduce the recovery of C. difficile CFUs. Finally, we determined the degree of colon pathology in the challenged mice with a cumulative histopathologic score, taking into account the presence and extent of inflammatory infiltrate, epithelial damage, and submucosal edema, as well as the number of intraepithelial lymphocytes, neutrophils, crypt abscesses, and lymph follicles (Supplemental Figure 6A in the Supporting Information). We did not take into account weight loss, which has been shown to be minimal or undetectable in mice upon $C$. difficile infection, ${ }^{38}$ nor stool consistency, as we focused on direct signs of inflammation in the colon. Histopathology showed mild (Supplemental Figure 6A, subpanel 1) to moderate (Supplemental Figure 6A, subpanels 2-7) signs of colitis in M68-infected and PBS-immunized mice. Moderate changes included the following: diffuse infiltration of the lamina propria by inflammatory immune cells (Supplemental Figure 6A, subpanels 3 and 4), submucosal edema (Supplemental Figure $6 \mathrm{~A}$, subpanel 5 (denoted by an asterisk, $*$ ), crypt abscesses (Supplemental Figure 6A, subpanel 6), and epithelial damage (Supplemental Figure 6A, subpanel 7). Vaccination with 1215 significantly ameliorated colitis; only mild signs were detected in vaccinated mice upon M68 infection, such as small localized infiltrates (subpanel 8, arrow) or lymph follicles with hyperplasia (Supplemental Figure 6A, subpanel 9, denoted by an arrow) at maximum. Examples for the detection of intraepithelial lymphocytes (Supplemental Figure 6A, subpanel 10 , denoted by an arrow) and tissue sections without pathological signs from uninfected (Supplemental Figure 6A, subpanel 11) and 15-vaccinated, infected mice (Supplemental Figure 6A, subpanel 12) are also shown. Animals vaccinated with 12-15 had significantly lower inflammatory scores than control mice, whereas $\mathrm{CRM}_{197}$ and $\mathbf{1 6}$ did not have a significant impact relative to PBS (Figure 3C). Inflammation 
was also reduced by the $\mathrm{TcdB}$ vaccine, but not as strongly as with 12-15. A significant correlation between $C$. difficile colonization and inflammation score suggested that reducing colonization was the main factor preventing CDI-mediated pathology in mice (Figure 3D).

We repeated challenge studies with strain M68 using mice immunized with Alum-adjuvanted 12 or 15; controls included mice treated with PBS, $\mathrm{CRM}_{197}$, or TcdB (seven mice per group). IgG1 production (Supplemental Figure $7 \mathrm{~A}$ in the Supporting Information), inhibition of colonization (Supplemental Figure $7 \mathrm{~B}$ in the Supporting Information) and reduction of inflammation (Supplemental Figure $7 \mathrm{C}$ in the Supporting Information) were comparable to the initial study. Vaccination with 12 and 15 again significantly reduced $C$. difficile colonization by 97.5 or $98.5 \%$, respectively, relative to the PBS group. In addition, colonization by VPI 10463, a highly virulent ribotype 087 strain $^{26,33}$ was significantly inhibited in mice vaccinated with 12 or $\mathbf{1 5}$ by $91.9 \%$ or $97.8 \%$, respectively, relative to $\mathrm{PBS}$, again with no impact on other bacteria like enterococci (Supplemental Figure 7B). Since VPI 10463 expresses both TcdA and TcdB, a group immunized with $\mathrm{TcdB}$ was omitted. Signs of inflammation caused by VPI 10463 were significantly reduced by vaccination with 12 and 15, compared to control groups (Supplemental Figure 7C). Histopathology revealed consistent (subpanels 13) signs of colitis in VPI 10463 infected mice ranging from mild changes (subpanel 1) to more severe changes (Supplemental Figure 7B, subpanel 3). Vaccination with 12 and 15 significantly ameliorated colitis (subpanels 4 and 5); colon sections showed either no pathological signs (subpanels $4,10)$ or only mild signs of colitis such as small localized infiltrates (subpanels 5, denoted by an asterisk, *). Histopathological changes in control groups included the following: focal mucosal lesions (subpanel 6, red arrowhead), formation of apoptotic bodies in epithelial cells (subpanel 7, black arrowheads), granulocyte infiltration (subpanel 7, green arrowhead) and diffuse infiltration of the lamina propria by inflammatory immune cells (subpanels 8 and 9).

Quantitative PCR (qPCR) using fecal DNA as a template and primers specific for toxin and 16S rRNA genes showed similar trends in intestinal colonization, as observed by enumerating CFUs for both strains; however, differences between vaccinated and control groups were not significant (Supplemental Figure 7D in the Supporting Information). As qPCR and CFU plating assays are reported to correlate well within the range of $10^{0}$ and $10^{5}$ bacteria, ${ }^{39}$ we conclude that, despite methodic variations, vaccinations may not only inhibit colonization with $C$. difficile, but also reduce bacterial viability.

To determine if protection was antibody-mediated and to minimize potential nonspecific effects by the vaccination, we performed challenge experiments following serum transfer and following active vaccination 4 weeks, instead of 2 weeks, after the third immunization (Figure 4A). Mice that received 13 mounted significant IgG responses to 2 , whereas control mice immunized with $\mathrm{CRM}_{197}$ did not (Figure 4B). As expected, mice immunized with $\mathbf{1 3}$ were significantly protected against colonization by VPI 10463 (Figure 4C). Pooled sera from these mice were transferred intraperitoneally into naïve animals that were challenged with VPI 10463. Pooled anti13 serum conferred substantial protection against colonization by $C$. difficile, compared to mice that received anti-CRM ${ }_{197}$ serum (Figure 4D). However, the low number of mice $(n=3)$ did not allow for statistical evaluation. Therefore, we repeated transfer experiments using pooled sera obtained from mice immunized with $\mathrm{CRM}_{197}$ or 13 (Figure $4 \mathrm{E}$ ). Mice that received PBS only served as additional controls. Six of 10 mice that received 13 mounted an IgG response against 2 detectable in serum diluted 1:100 (Figure 4F). Three out of four of the remaining animals had detectable anti-2 IgG signals when sera were analyzed at 1:10 dilution (Figure S8 in the Supporting Information). Pooled sera of mice immunized with 13 significantly protected mice from colonization by VPI 10463 after serum transfer (Figure 4G). In addition, monoclonal antibody $(\mathrm{mAb}) 2 \mathrm{C} 5$ against $\mathbf{1}^{20}$ significantly protected from colonization, whereas a mAb against a glycan epitope of Streptococcus pneumoniae ${ }^{40}$ did not.

Employing a microarray protocol that we previously used to identify secreted antibodies to $C$. difficile glycans in human stool, ${ }^{19}$ we did not detect glycan-specific IgG or IgA in feces of immunized mice before challenge (Supplemental Figures 9A and $9 \mathrm{~B}$ in the Supporting Information). However, we identified anti-CRM ${ }_{197}$ IgG in the same samples by ELISA (Supplemental Figure 9C in the Supporting Information), which is a more sensitive technique. ${ }^{41}$ This suggests that small amounts of vaccine-induced protective antibodies were present in the intestinal lumen before infection. In addition, antibody transport through the epithelium may have been promoted by toxin-induced tissue damage during infection, as shown previously. ${ }^{42-44}$

Conclusions. In summary, we showed that semisynthetic glycoconjugates protected mice, one of the most widely used small animal models for C. difficile, ${ }^{26}$ from CDI more effectively than a toxoid-based vaccine. We selected the mouse model, because, similar to humans, mice allow for replication of $C$. difficile in the colon and develop an inflammatory response. ${ }^{26}$ The degree of protection was comparable for both tested strains: M68 and VPI 10463. Most importantly, vaccination with glycoconjugates, but not with toxoid, significantly reduced intestinal colonization with C. difficile. Passive immunization studies with immune sera and mAbs demonstrated that protection was, at least partially, mediated by $C$. difficile-specific antibodies. Of note, we did not detect significant binding of the raised polyclonal sera to inactivated bacteria, as measured by flow cytometry. This may have been due to the weak and inconsistent polysaccharide expression levels in vitro ${ }^{8}$, which may be lower than their in vivo expression. In addition, inactivation of the bacteria with formalin may have destroyed important epitopes. Another possibility is that binding of the oligosaccharide-specific antibodies may have been too weak to be detectable by the experimental setup that was employed, but strong enough to confer protection in vivo. Refining the synthetic oligosaccharides, such as including a terminal phosphate group in the PS-II hexasaccharide repeating unit, as previously reported, ${ }^{14}$ may help to elicit antibodies that recognize the native polysaccharide with higher affinity and to enhance antibodymediated protective efficacy. Our data also suggests that antibody-independent mechanisms, such as cellular cognate immune responses, contribute to the protection against $C$. difficile infection in the mouse model, since some mice exhibited even clinical improvement in the absence of detectable glycan-specific antibody titers.

Using synthetic oligosaccharides overcame the shortage of natural polysaccharides due to weak in vitro expression, particularly of PS-I and PS-III. ${ }^{8}$ Initially solely identified on an isolate of ribotype $027 \mathrm{C}$. difficile, PS-I was originally 
suggested to be strain-specific. ${ }^{12}$ The subsequent detection on other, nonribotype 027 strains $^{45}$ and the frequent presence of PS-I specific serum antibodies in horses ${ }^{46}$ and humans, ${ }^{19}$ however, indicates that PS-I is likely commonly expressed by various $C$. difficile strains in vivo. PS-II is recognized as a ubiquitous polysaccharide that has been identified on all $C$. difficile isolates investigated so far. ${ }^{12,45}$ PS-III is likely also commonly expressed by $C$. difficile, since antibodies raised with this polysaccharide in rabbits recognized a wide range of C. difficile strains. ${ }^{15}$ Importantly, our studies revealed that vaccination with the various glycoconjugates of PS-I, PS-II, and PS-III did not significantly affect the murine intestinal microbiota, indicating that the elicited antibodies are highly specific to $C$. difficile. We also demonstrated that the anti-PS-I $\mathrm{mAb} 2 \mathrm{C} 5$ significantly protected mice from $C$. difficile colonization, which raises the possibility of their potential therapeutic use, perhaps in combination with antitoxin mAbs that have shown promise against CDI in clinical trials. ${ }^{8}$

The feasibility of large-scale production of glycoconjugate vaccines with synthetic glycan antigens has been demonstrated by the Qiumi-Hib vaccine against Haemophilus influenzae type $\mathrm{B}$ marketed in Cuba. ${ }^{47}$ In addition, the carrier protein used here, $\mathrm{CRM}_{197}$, is well-characterized, safe, and has been used in various marketed glycoconjugate vaccines. ${ }^{23}$

Toxoid vaccines alone efficiently reduce CDI symptoms in humans ${ }^{7,29}$ but could increase the number of asymptomatic carriers that may spread C. difficile to vulnerable individuals. ${ }^{8,9}$ Combining both vaccine strategies may be the most effective measure to fight CDI. ${ }^{48}$

\section{EXPERIMENTAL METHODS}

Detailed information for all methods used can be found in the Supporting Information.

\section{ASSOCIATED CONTENT}

\section{S Supporting Information}

The Supporting Information is available free of charge on the ACS Publications website at DOI: 10.1021/acschembio.9b00642.

Experimental procedures; additional references; supplementary table and figures (PDF)

\section{AUTHOR INFORMATION}

\section{Corresponding Author}

*E-mail: peter.seeberger@mpikg.mpg.de.

\section{ORCID *}

Peter H. Seeberger: 0000-0003-3394-8466

\section{Present Addresses}

${ }^{\star}$ Vaxxilon Deutschland GmbH, Magnusstr. 11, 12489 Berlin, Germany.

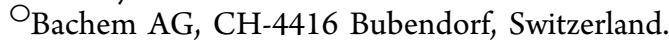

\section{Author Contributions}

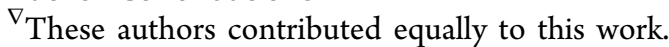

\section{Notes}

The authors declare the following competing financial interest(s): F.B., C.E.M., and P.H.S. are inventors on patent PCT/EP2012/003240 held by the Max Planck Gesellschaft zur Forderung der Wissenschaften e.V. that covers synthetic vaccines against $C$. difficile. P.H.S. declares a significant financial interest in Vaxxilon, the company that commercializes the $C$. difficile vaccine candidates described here. However, there is no conflict of interest, since this is a purely scientific manuscript that was not sponsored by the company.

\section{ACKNOWLEDGMENTS}

We gratefully acknowledge generous financial support from the Max Planck Society, the German Federal Ministry of Education and Research (Grant No. 0315447 to P.H.S.), the Deutsche Forschungsgemeinschaft (No. SFB-TR84 C8 (to P.H.S.), Nos. DFG-CRC1181-C04 and DFG-MA 2621/4-1 (to J.M.), and DFG-CRC796-B01 and DFG EN 423/5-1 (to A.E.)), the Staedtler Stiftung and the Johannes and Frieda Marohn Stiftung (to J.M.) and the Körber Foundation (Körber Prize, to P.H.S.). A.E. also acknowledges funding by IZKF Erlangen A66. We thank J. Y. Baek for synthesizing 3 and Y. Yang for synthesizing 5. We thank C. Giessler for performing qPCR analyses.

\section{REFERENCES}

(1) Kelly, C. P., and LaMont, J. T. (2008) Clostridium difficile more difficult than ever. N. Engl. J. Med. 359, 1932-1940.

(2) Lessa, F. C., Mu, Y., Bamberg, W. M., Beldavs, Z. G., Dumyati, G. K., Dunn, J. R., Farley, M. M., Holzbauer, S. M., Meek, J. I., Phipps, E. C., Wilson, L. E., Winston, L. G., Cohen, J. A., Limbago, B. M., Fridkin, S. K., Gerding, D. N., and McDonald, L. C. (2015) Burden of Clostridium difficile infection in the United States. N. Engl. J. Med. 372, 825-834.

(3) Kelly, C. P. (2012) Can we identify patients at high risk of recurrent Clostridium difficile infection? Clin. Microbiol. Infect. 18 (Suppl 6), 21-27.

(4) Pépin, J., Saheb, N., Coulombe, M. A., Alary, M. E., Corriveau, M. P., Authier, S., Leblanc, M., Rivard, G., Bettez, M., Primeau, V., Nguyen, M., Jacob, C. E., and Lanthier, L. (2005) Emergence of fluoroquinolones as the predominant risk factor for Clostridium difficile-associated diarrhea: a cohort study during an epidemic in Quebec. Clin. Infect. Dis. 41, 1254-1260.

(5) Khoruts, A., and Sadowsky, M. J. (2016) Understanding the mechanisms of faecal microbiota transplantation. Nat. Rev. Gastroenterol. Hepatol. 13, 508-516.

(6) Aslam, S., Hamill, R. J., and Musher, D. M. (2005) Treatment of Clostridium difficile-associated disease: old therapies and new strategies. Lancet Infect. Dis. 5, 549-557.

(7) Leuzzi, R., Adamo, R., and Scarselli, M. (2014) Vaccines against Clostridium difficile. Hum. Vaccines Immunother. 10, 1466-1477.

(8) Monteiro, M. A., Ma, Z., Bertolo, L., Jiao, Y., Arroyo, L., Hodgins, D., Mallozzi, M., Vedantam, G., Sagermann, M., Sundsmo, J., and Chow, H. (2013) Carbohydrate-based Clostridium difficile vaccines. Expert Rev. Vaccines 12, 421-431.

(9) Kyne, L., Warny, M., Qamar, A., and Kelly, C. P. (2000) Asymptomatic carriage of Clostridium difficile and serum levels of IgG antibody against toxin A. N. Engl. J. Med. 342, 390-397.

(10) He, M., Miyajima, F., Roberts, P., Ellison, L., Pickard, D. J., Martin, M. J., Connor, T. R., Harris, S. R., Fairley, D., Bamford, K. B., D’Arc, S., Brazier, J., Brown, D., Coia, J. E., Douce, G., Gerding, D., Kim, H. J., Koh, T. H., Kato, H., Senoh, M., Louie, T., Michell, S., Butt, E., Peacock, S. J., Brown, N. M., Riley, T., Songer, G., Wilcox, M., Pirmohamed, M., Kuijper, E., Hawkey, P., Wren, B. W., Dougan, G., Parkhill, J., and Lawley, T. D. (2013) Emergence and global spread of epidemic healthcare-associated Clostridium difficile. Nat. Genet. 45, 109-113.

(11) Chu, M., Mallozzi, M. J., Roxas, B. P., Bertolo, L., Monteiro, M. A., Agellon, A., Viswanathan, V. K., and Vedantam, G. (2016) A Clostridium difficile Cell Wall Glycopolymer Locus Influences Bacterial Shape, Polysaccharide Production and Virulence. PLoS Pathog. 12, e1005946.

(12) Ganeshapillai, J., Vinogradov, E., Rousseau, J., Weese, J. S., and Monteiro, M. A. (2008) Clostridium difficile cell-surface polysacchar- 
ides composed of pentaglycosyl and hexaglycosyl phosphate repeating units. Carbohydr. Res. 343, 703-710.

(13) Reid, C. W., Vinogradov, E., Li, J., Jarrell, H. C., Logan, S. M., and Brisson, J. R. (2012) Structural characterization of surface glycans from Clostridium difficile. Carbohydr. Res. 354, 65-73.

(14) Adamo, R., Romano, M. R., Berti, F., Leuzzi, R., Tontini, M., Danieli, E., Cappelletti, E., Cakici, O. S., Swennen, E., Pinto, V., Brogioni, B., Proietti, D., Galeotti, C. L., Lay, L., Monteiro, M. A., Scarselli, M., and Costantino, P. (2012) Phosphorylation of the synthetic hexasaccharide repeating unit is essential for the induction of antibodies to Clostridium difficile PSII cell wall polysaccharide. ACS Chem. Biol. 7, 1420-1428.

(15) Cox, A. D., St. Michael, F., Aubry, A., Cairns, C. M., Strong, P. C., Hayes, A. C., and Logan, S. M. (2013) Investigating the candidacy of a lipoteichoic acid-based glycoconjugate as a vaccine to combat Clostridium difficile infection. Glycoconjugate J. 30, 843-855.

(16) Oberli, M. A., Hecht, M. L., Bindschädler, P., Adibekian, A., Adam, T., and Seeberger, P. H. (2011) A possible oligosaccharideconjugate vaccine candidate for Clostridium difficile is antigenic and immunogenic. Chem. Biol. 18, 580-588.

(17) Martin, C. E., Weishaupt, M. W., and Seeberger, P. H. (2011) Progress toward developing a carbohydrate-conjugate vaccine against Clostridium difficile ribotype 027: synthesis of the cell-surface polysaccharide PS-I repeating unit. Chem. Commun. (Cambridge, $U$. K.) 47, 10260-10262.

(18) Martin, C. E., Broecker, F., Eller, S., Oberli, M. A., Anish, C., Pereira, C. L., and Seeberger, P. H. (2013) Glycan arrays containing synthetic Clostridium difficile lipoteichoic acid oligomers as tools toward a carbohydrate vaccine. Chem. Commun. (Cambridge, U. K.) 49, 7159-7161.

(19) Martin, C. E., Broecker, F., Oberli, M. A., Komor, J., Mattner, J., Anish, C., and Seeberger, P. H. (2013) Immunological evaluation of a synthetic Clostridium difficile oligosaccharide conjugate vaccine candidate and identification of a minimal epitope. J. Am. Chem. Soc. 135, 9713-9722.

(20) Broecker, F., Hanske, J., Martin, C. E., Baek, J. Y., Wahlbrink, A., Wojcik, F., Hartmann, L., Rademacher, C., Anish, C., and Seeberger, P. H. (2016) Multivalent display of minimal Clostridium difficile glycan epitopes mimics antigenic properties of larger glycans. Nat. Commun. 7, 11224.

(21) Broecker, F., Martin, C. E., Wegner, E., Mattner, J., Baek, J. Y., Pereira, C. L., Anish, C., and Seeberger, P. H. (2016) Synthetic lipoteichoic acid glycans are potential vaccine candidates to protect from Clostridium difficile infections. Cell Chem. Biol. 23, 1014-1022.

(22) Möginger, U., Resemann, A., Martin, C. E., Parameswarappa, S., Govindan, S., Wamhoff, E. C., Broecker, F., Suckau, D., Pereira, C. L., Anish, C., Seeberger, P. H., and Kolarich, D. (2016) Cross Reactive Material 197 glycoconjugate vaccines contain privileged conjugation sites. Sci. Rep. 6, 20488.

(23) Astronomo, R. D., and Burton, D. R. (2010) Carbohydrate vaccines: developing sweet solutions to sticky situations? Nat. Rev. Drug Discovery 9, 308-324.

(24) Reinhardt, A., Yang, Y., Claus, H., Pereira, C. L., Cox, A. D. Vogel, U., Anish, C., and Seeberger, P. H. (2015) Antigenic potential of a highly conserved Neisseria meningitidis lipopolysaccharide inner core structure defined by chemical synthesis. Chem. Biol. 22, 38-49.

(25) Wu, X., Ling, C. C., and Bundle, D. R. (2004) A new homobifunctional $p$-nitro phenyl ester coupling reagent for the preparation of neoglycoproteins. Org. Lett. 6, 4407-4410.

(26) Hutton, M. L., Mackin, K. E., Chakravorty, A., and Lyras, D. (2014) Small animal models for the study of Clostridium difficile disease pathogenesis. FEMS Microbiol. Lett. 352, 140-149.

(27) Del Giudice, G., and Rappuoli, R. (2014) Inactivated and adjuvanted influenza vaccines. Curr. Top. Microbiol. Immunol. 386, $151-180$.

(28) Drudy, D., Harnedy, N., Fanning, S., O’Mahony, R., and Kyne, L. (2007) Isolation and characterisation of toxin A-negative, toxin Bpositive Clostridium difficile in Dublin, Ireland. Clin. Microbiol. Infect. 13, 298-304.
(29) de Bruyn, G., Saleh, J., Workman, D., Pollak, R., Elinoff, V., Fraser, N. J., Lefebvre, G., Martens, M., Mills, R. E., Nathan, R., Trevino, M., van Cleeff, M., Foglia, G., Ozol-Godfrey, A., Patel, D. M., Pietrobon, P. J., and Gesser, R. (2016) Defining the optimal formulation and schedule of a candidate toxoid vaccine against Clostridium difficile infection: A randomized Phase 2 clinical trial. Vaccine 34, 2170-2178.

(30) Torres, J. F., Lyerly, D. M., Hill, J. E., and Monath, T. P. (1995) Evaluation of formalin-inactivated Clostridium difficile vaccines administered by parenteral and mucosal routes of immunization in hamsters. Infect. Immun. 63, 4619-4627.

(31) Broecker, F., Klumpp, J., and Moelling, K. (2016) Long-term microbiota and virome in a Zürich patient after fecal transplantation against Clostridium difficile infection. Ann. N. Y. Acad. Sci. 1372, 2941.

(32) Etienne-Mesmin, L., Chassaing, B., Adekunle, O., Mattei, L. M., Bushman, F. D., and Gewirtz, A. T. (2018) Toxin-positive Clostridium difficile latently infect mouse colonies and protect against highly pathogenic C. difficile. Gut 67, 860-871.

(33) Buffie, C. G., Jarchum, I., Equinda, M., Lipuma, L., Gobourne, A., Viale, A., Ubeda, C., Xavier, J., and Pamer, E. G. (2012) Profound alterations of intestinal microbiota following a single dose of clindamycin results in sustained susceptibility to Clostridium difficile-induced colitis. Infect. Immun. 80, 62-73.

(34) Lawley, T. D., Clare, S., Walker, A. W., Goulding, D., Stabler, R. A., Croucher, N., Mastroeni, P., Scott, P., Raisen, C., Mottram, L., Fairweather, N. F., Wren, B. W., Parkhill, J., and Dougan, G. (2009) Antibiotic treatment of Clostridium difficile carrier mice triggers a supershedder state, spore-mediated transmission, and severe disease in immunocompromised hosts. Infect. Immun. 77, 3661-3669.

(35) Abt, M. C., Lewis, B. B., Caballero, S., Xiong, H., Carter, R. A., Sušac, B., Ling, L., Leiner, I., and Pamer, E. G. (2015) Innate Immune Defenses Mediated by Two ILC Subsets Are Critical for Protection against Acute Clostridium difficile Infection. Cell Host Microbe 18, $27-$ 37.

(36) Malley, R., Trzcinski, K., Srivastava, A., Thompson, C. M., Anderson, P. W., and Lipsitch, M. (2005) $\mathrm{CD}^{+}{ }^{+} \mathrm{T}$ cells mediate antibody-independent acquired immunity to pneumococcal colonization. Proc. Natl. Acad. Sci. U. S. A. 102, 4848-4853.

(37) Trzciński, K., Thompson, C. M., Srivastava, A., Basset, A., Malley, R., and Lipsitch, M. (2008) Protection against nasopharyngeal colonization by Streptococcus pneumoniae is mediated by antigenspecific $\mathrm{CD}^{+}{ }^{+} \mathrm{T}$ cells. Infect. Immun. 76, 2678-2684.

(38) Shelby, R. D., Tengberg, N., Conces, M., Olson, J. K., Navarro, J. B., Bailey, M. T., Goodman, S. D., and Besner, G. E. (2019) Development of a standardized scoring system to assess a murine model of Clostridium difficile colitis. J. Invest. Surg. Mar 20, 1-9.

(39) Matsuda, K., Tsuji, H., Asahara, T., Kado, Y., and Nomoto, K. (2007) Sensitive quantitative detection of commensal bacteria by rRNA-targeted reverse transcription-PCR. Appl. Environ. Microbiol. $73,32-39$.

(40) Schumann, B., Hahm, H. S., Parameswarappa, S. G., Reppe, K., Wahlbrink, A., Govindan, S., Kaplonek, P., Pirofski, L. A., Witzenrath, M., Anish, C., Pereira, C. L., and Seeberger, P. H. (2017) A semisynthetic Streptococcus pneumoniae serotype 8 glycoconjugate vaccine. Sci. Transl. Med. 9 (380), pii: eaaf5347.

(41) Wilson, R. (2013) Sensitivity and specificity: twin goals of proteomics assays. Can they be combined? Expert Rev. Proteomics 10, 135-149.

(42) Leav, B. A., Blair, B., Leney, M., Knauber, M., Reilly, C., Lowy, I., Gerding, D. N., Kelly, C. P., Katchar, K., Baxter, R., Ambrosino, D., and Molrine, D. (2010) Serum anti-toxin B antibody correlates with protection from recurrent Clostridium difficile infection (CDI). Vaccine 28, 965-969.

(43) Navalkele, B. D., and Chopra, T. (2018) Bezlotoxumab: an emerging monoclonal antibody therapy for prevention of recurrent Clostridium difficile infection. Biol.: Targets Ther. 12, 11-21.

(44) Zhang, Z., Chen, X., Hernandez, L. D., Lipari, P., Flattery, A., Chen, S. C., Kramer, S., Polishook, J. D., Racine, F., Cape, H., Kelly, 
C. P., and Therien, A. G. (2015) Toxin-mediated paracellular transport of antitoxin antibodies facilitates protection against Clostridium difficile infection. Infect. Immun. 83, 405-416.

(45) Bertolo, L., Boncheff, A. G., Ma, Z., Chen, Y. H., Wakeford, T., Friendship, R. M., Rosseau, J., Weese, J. S., Chu, M., Mallozzi, M., Vedantam, G., and Monteiro, M. A. (2012) Clostridium difficile carbohydrates: glucan in spores, PSII common antigen in cells, immunogenicity of PSII in swine and synthesis of a dual C. difficileETEC conjugate vaccine. Carbohydr. Res. 354, 79-86.

(46) Jiao, Y., Ma, Z., Hodgins, D., Pequegnat, B., Bertolo, L., Arroyo, L., and Monteiro, M. A. (2013) Clostridium difficile PSI polysaccharide: synthesis of pentasaccharide repeating block, conjugation to exotoxin B subunit, and detection of natural anti-PSI IgG antibodies in horse serum. Carbohydr. Res. 378, 15-25.

(47) Verez-Bencomo, V., Fernández-Santana, V., Hardy, E., Toledo, M. E., Rodríguez, M. C., Heynngnezz, L., Rodriguez, A., Baly, A., Herrera, L., Izquierdo, M., Villar, A., Valdés, Y., Cosme, K., Deler, M. L., Montane, M., Garcia, E., Ramos, A., Aguilar, A., Medina, E., Toraño, G., Sosa, I., Hernandez, I., Martínez, R., Muzachio, A., Carmenates, A., Costa, L., Cardoso, F., Campa, C., Diaz, M., and Roy, R. (2004) A synthetic conjugate polysaccharide vaccine against Haemophilus influenzae type b. Science 305, 522-525.

(48) Romano, M. R., Leuzzi, R., Cappelletti, E., Tontini, M., Nilo, A., Proietti, D., Berti, F., Costantino, P., Adamo, R., and Scarselli, M. (2014) Recombinant Clostridium difficile toxin fragments as carrier protein for PSII surface polysaccharide preserve their neutralizing activity. Toxins 6, 1385-1396. 